\title{
MANAGEMENT OF RHEGMATOGENOUS RETINAL DETACHMENT WITH BUCKLE SCLERA AND CRYORETINOPEXCY
}

\author{
Ria Mutiara, Ramzi Amin \\ Department of Ophthalmology, Universitas Sriwijaya
}

\begin{abstract}
Introduction: Retinal detachment is divided into three categories. The most common type is the regmatogen retinal detachment (rhegmatogenous retinal detachment), which is the result of the tearing of the retinal lining. Actions can be Buckle Sclera, vitrectomy pars plana and pneumatic retinopexy. The purpose of this case report to reported Management of Rhegmatogenous Retinal detachment with Buckle Sclera and Cryoretinopexcy.
\end{abstract}

Method: $A 58$ years old man with chief complaint The left eye blurred like a curtain covered since 5 days, floaters (+), photopsia (+), headache (+), Patients never complain of lost vision suddenly before, eyeball pain is not there.History of trauma (+), On examination, the visual acuity 6/9 RE and 1/60 LE, anterior segment lens cloudy (+)nuclaer gr III, fundus photograph we found retinal contours of the blood vessels well, tear (+) is directed at 2-3 hours of superior-temporal and fovea reflex (-), B-scan ultrasound of the posterior segment the retina is not intact, Membran like lession detachment which attach to optic nerve.

Results: The Sclera buckles and cryoretinopexy were performed under general antesthesia. Visual acuity post-operative on left eye 2/60. subconjunctival bleeding (+), the fundus photographs retinal attach but the macular reflex is still negative. post-operative theraphy with topical steroid and antibiotic eye drops, oral antibiotic, and oral analgetic. follow up 1-month post-operative visual acuity 5/60 with fundus photograph obtained retina attach.

Conclusion: a diagnosis of retinal detachment can be found, with the discovery of fullthickness breaks or defects occurring from the retinal neurosensory, this break will allow the vitreous to enter the defect gap between the retinal neurosensory and RPE. Based on the clinical features of the posterior segment, the detachment area was found with the location of the Linchoff Rule 2 break based on the American Academy of Ophthalmology. The objective of operative therapy was to reattach the retinal portion of which one of them was buckle sclera and cryoretinopexcy.

Keywords: retinal detachments, buckle sklera, cryoretinopexy

Cite This Article: MUTIARA, ria mutiara. Management of Rhegmatogenous Retinal detachment with Buckle Sclera and Cryoretinopexcy. International Journal of Retina, [S.I.], v. 2, n. 1, aug. 2018. ISSN 2614-8536. Available at: $<$ https://www.ijretina.com/index.php/ijretina/article/view/33>.

*Correspondence to:

Ria Mutiara,

Department of Ophthalmology,

Universitas Sriwijaya,

Ria.mutiara26@gmail.com

\section{INTRODUCTION}

Retinal detachment is divided into three categories. The most common type is the regmatogen retinal detachment (rhegmatogenous retinal detachment), which is the result of the tearing of the retinal lining. The second category is the tractional retinal detachment based on the occurrence of vitreous attachment with the retina which results in the pull of neurosensory from RPE. In certain circumstances there may be a combination of regmatogen and tractional. The third category is the exudative retinal detachment associated with the inflammatory process, malignancy. In this type of exudation occurs the accumulation of subretinal fluid which ends in the release of the retinal layer. ${ }^{1-3}$

Epidemiological data in the United States the incidence of retinal detachment was 12.5 cases per 10,000 per year. Approximately 40$50 \%$ of cases occur with myopia risk factor, 30 $40 \%$ with history of cataract surgery and 10 $20 \%$ is ocular injury. Cases of trauma occur most at the age of the child and cases with myopia often occur at the age of 25-40 years., 
The operative management principle of the retinal detachment is to glue back the loose retinal layer by previously identifying and closing when there is a retinal tear and release of traction from vitreoretina. Actions can be Buckle Sclera, vitrectomy pars plana and pneumatic retinopexy. The consideration of the choice of operative therapy depends on the underlying pathogenesis of each case of retinal detachment. ${ }^{4,5}$

\section{METHOD}

Patient A 58 years old man, with medical record 105776 come to the eye polyclinic on 25 January 2018, with chief Complaint the left eye blurred like a partially covered curtain since 5 days, Since 5 days ago the patient complained of sudden blurred vision on the left eye. Complaints in without red eyes. Vision is felt like a closed curtain. Complaints are felt after the patient fell in the field while working 8 days ago, Since \pm 6 days ago complained to the left eye floters $(+)$, photopsia $(+)$. headache $(+)$, Patients never complain of sudden loss of vision before, pain in the eyeball (-). History of trauma (+), visual acuity $6 / 9 \mathrm{RE}, 1 / 60 \mathrm{LE}$, intraocular pressure in normal limit, claudy lens nuclear gr III,posterior segment retinal contours of the blood vessels well, tear $(+)$ is directed at 2-3 hours of superior-temporal and fovea reflex (-), B-scan ultrasound of the posterior segment the retinal is not intact, Membran like lession detachment which attach to optic nerve

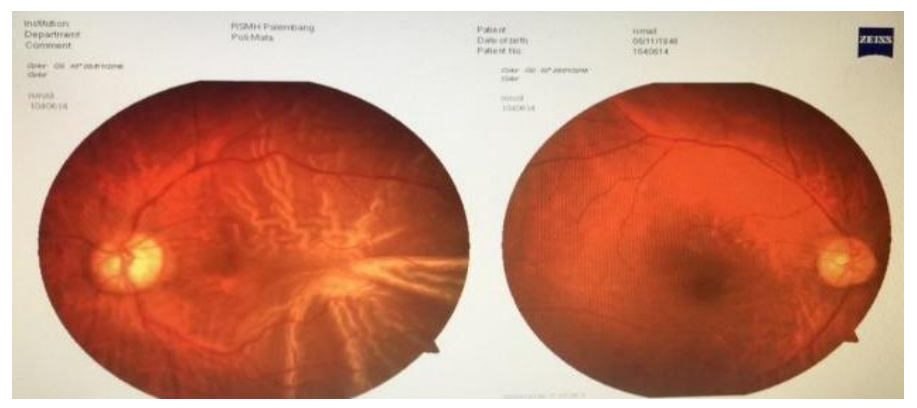

Figure 1: Fundus Photograph Right Eye Tear (+) is Directed At 2-3 Hours Of Superior-Temporal and Left Eye In Normal Limit

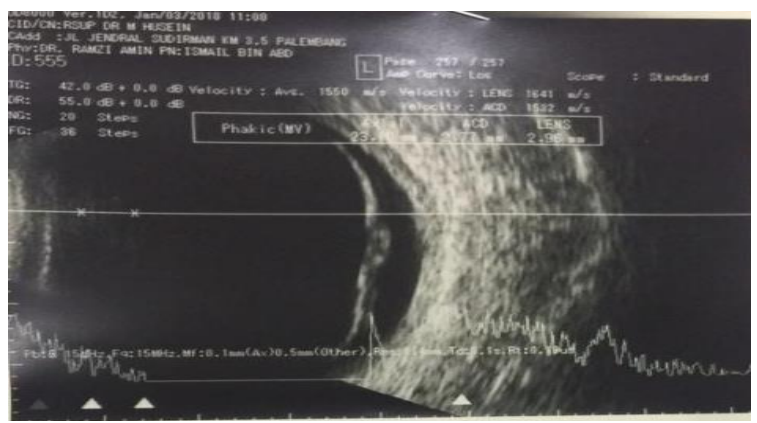

Figure 2 : B-Scan Ultrasound of The Posterior Segment Pre Operative Retinal is not Intact, Membran Like Lession

\section{Detachment Which Attach to Optic Nerve}

\section{RESULT}

Buckle sclera with cryoretinopexcy were perfomed in rhegmatogenous retinal detachment. The installation of the encircling band surrounds the eyeball under the rectus muscle and the tyre band from 1 to 5 hours through the bottom of the inferior, and lateral, with visual acuity post operative $2 / 60$, subconjunctival bleeding $(+)$, the fundus photograph retinal attach but the macular reflex is still negative. at 1 month follow up examination fundus photograph and B-scan ultrasound obtained retinal attach, but reflex fovea still negative. 


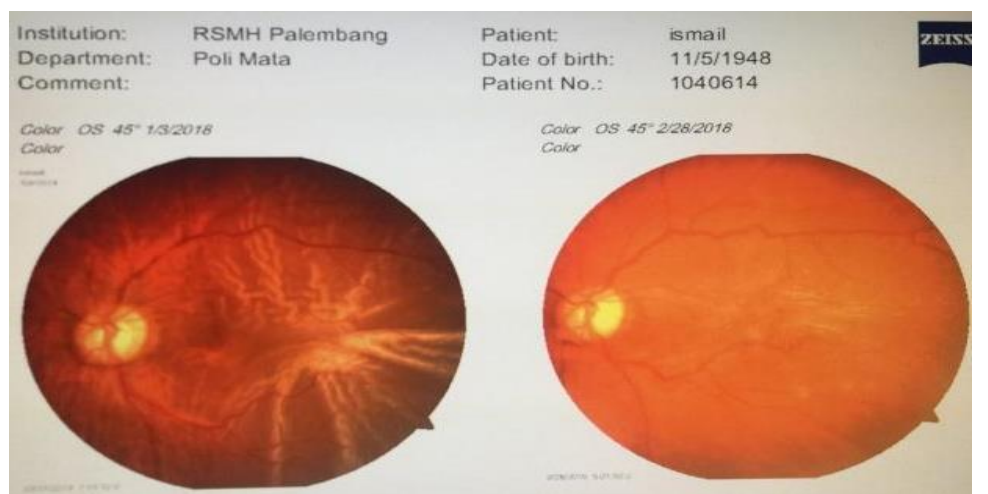

Figure 3 : Pre and Post Operative Retinal Fundus Photograph, Post Operatif Retinal Attach But The Macular Reflex is Still Negative

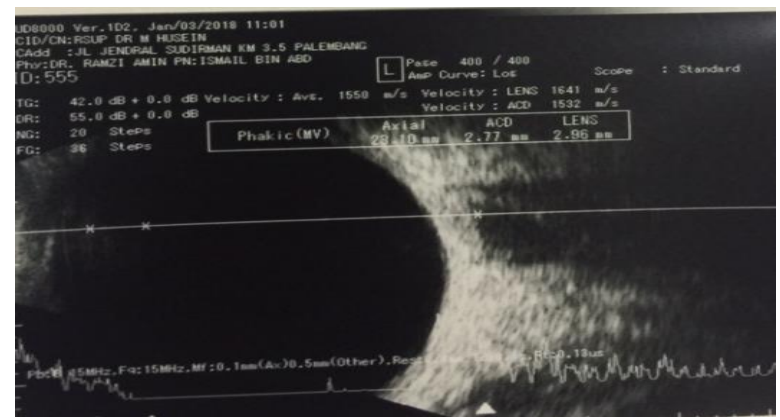

Figure 4 : B-Scan Ultrasound of The Posterior Segment Post Operative Retinal Attach

\section{DISCUSSION}

In anamnesa obtained right eye complaints blurred suddenly since 5 days ago, blurred vision felt like closed the complaint curtain felt after the patient fell. Found complaint view like seeing flash of light. in the literature it is mentioned that the typical signs and symptoms of the retina detachment are usually preceded by floaters, flash / photopsia due to mechanical stimuli that occur from vitreoretinal traction that is detached from the retina, narrowed viewing field and blurred vision. According to Johannes Arnoldus, Groningen University, said the risk factor of rhegmatogen retinal detachment highest incidence more in men, the average age with the highest incidence of 55-65 years. ${ }^{5.15-18}$

An ophthalmologic examination was performed to determine the diagnosis in the viscous patient $1 / 60$ ph (). Then in the posterior segment of the funduscopic examination obtained normal papillary area, no fovea reflex in the macula and obtained a break in the superotemporal retina at the area of 2 and 3 hours.

Diagnostic leads to ablatio retina rhegmatogen due to a break that causes partial accumulation of fluid subretinally, ablation of tracional abnormalities may be excluded in patients with diabetes mellitus, ablation of exudative retina due to malignancy or inflammatory disease whereas in these patients no systemic abnormalities, malignancies and ocular inflammatory disease. Based on the clinical picture of the posterior segment found detachment area. These fundus photo shots are also adjusted for break locations with Linchoff Rules 2 based on the American Academy of Ophthalmology, diagnostic and advanced management. 5,6,9,10,15-23

Scleral buckling technique can be chosen because of the break position found and the retinal loss of 1-2 quadrants. According to Martinez et al, added pars plana vitrectomy, this operative combination is performed to reduce the risk of failure or recurrent retinal ablatio and a better prognosis than buckle sclera alone. According to Garcia's article, Arumia et al, reporting the results of this combined surgery provides a successful retinal attached operation of $96 \%$, the risk of recurrent retinal ablation is lower and cryoretinopexcy is needed in the area around the retinal break, to prevent the vitreous from entering the retina and attaching the retina to choroid. Use of general anesthesia is done to prevent the occurrence of complications that may occur intraoperatif. ${ }^{6,-8,15,20,23}$

follow-up assessed is visus progress, intraocular pressure, silicon oil condition (this condition can be seen 6-12 months postoperatively), retina attached or not and also need to assess the optical condition of the patient to assess the optic nerve. ${ }^{1,15,16,21,22}$ 
The prognosis in this patient is quo ad vitam dubia ad bonam. If the patient presents with ablatio retina rhegmatogen with initial visus $1 / 60$ to $5 / 60$. This is adjusted to the prognosis of patients with post-traumatic retinal post ablatio from 8 days to surgery. Improvement of the visus we expect according to study from Martinez, et al if involving macula then can reach the final visus 6 /30. 8,20,21,23

\section{CONCLUSION}

The rhegmatogen-type retina ablatio is the most common form that can lead to a fullthickness retinal break. In retinal ablatio therapy given depends on the risk factors that accompany buckle sclera with cryoretinopexy is one of the treatment options in the retina ablatio. Combination operative therapy is selected to minimize the complications that can occur. Patients are encouraged to follow-up regularly every month to evaluate postoperative long-term success.

\section{REFERENCES}

1. Liesegang T J. Basic and Clinical Science Course. Section 12. Retina and Vitreous. The foundation of the American Academy of Ophthalmology; 2014-2015

2. Iwase $T$, Jo YJ, Oveson BC. Effect of prophylactic $360^{\circ}$ laser treatment for prevention of retinal detachment after phacovitrectomy: prophylactic $360^{\circ}$ laser treatment for prevention of retinal detachment. BMC Ophthal-mol. 2013;10(13):77.

3. Yang HS, Kim YJ, Kim JG. New prophylactic intraoperative septated circumferential barrier laser in macular surgery. Can J Ophthalmol. 2016;51(2):102-7

4. Bouheraoua Nacim, Hrarat Linda, Parsa Cameron $F$, et al. Decreased corneal sensation and subbasal nerve density, and thinned corneal epithelium as a result of 360-degree laser retinopexy. Ophthalmology. 2015;122(10):2095-102

5. Martínez-Castillo VJ, García-Arumí J, Boixadera A. Pars plana vitrectomy alone for the management of pseudophakic rhegmatogenous retinal detachment with only inferior breaks. Ophthalmology. 2016;123(7):1563-9.

6. Ryan SJ. Retinal Reattachment: Surgical Principles and Technique. Surgical retina. Retina. Fourth edition. Vol.3. 2005

7. Regillo CD, Brown GC, Flynn HW. Vitreoretinal Disease; The Essentials. New York-Stuttgart 1999

8. Peyman GA, Meffert SA, Conway MD. Surgical Techniques for The Treatment of Retinal Tears and Complicated Retinal Detachment Vitreoretinal Surgical Techniques. Second Edition. New Orleans, LA, USA.2007

9. Kanski JJ. Clinical Ophthalmology. Seventh edition. Chapter 16. Retinal Detachment; 2011

10. Williamson TH. Rhegmatogenous Retinal Detachment. Vitreoretinal Surgery. Springer. London 2007

11. Chou T, Siegel M. The Mechanics of Retinal Detachment. New Jersey Institute of Technology, Newark, NJ, 07102-1982

12. Lai TYY. Retinal Complications of High Myopia. The Hongkong Medical Diary.2007

13. Lewkonia,M.S, Davies, J.D.Salmon. British Journal Ophthalmology. Lattice degeneration in a family with retinal detachment and cataract. Sept 1973

14. Lattice degeneration. Conditions and Diseases. (http://www.retinalmd.com/en/resources/conditi ons-and-disease). Download at 4th December 2016

15. Gout I, Mellington F, Tah V et al. Retinal Detachment-An Updat of the Disease and Its Epidemilogy-A Discussion on Research and Clinical Experience at The Prince Charles Eye Unit, Windsor, England. Oxford University, England.2011

16. Jain $P$, Nagpal $M$, Videkar $R$, Patil A. Evaluation of Possible Risk Factors for Retinal Re-Detachment after Silicone Oil Removal.AIOC 2010

17. Mehdizadeh $M$, Afarid M, Haghighi MS. Retinal Redetachment after Cataract Surgery in eyes with Previous Skleral Buckling. Journal of Ophthalmic and Vision Research 2011;vol. 6

18. Schwartz SG, Flynn HW. Primary retinal detachment: scleral buckle or pars plana vitrectomy? Curr Opinion Ophthalmol. 20011;17:245-50.

19. Burton TC. The influence of refractive error and lattice degeneration on the incidence of retinal detachment. Trans Am Ophthalmol Soc. 1989;87:143-157.

20. Connolly BP, Regillo CD. Rhegmatogenous retinal detachment. In: Tansman W, Jaeger EA, eds. Duane's Ophthalmology. 2013 ed. Philadelphia, PA: Lippincott Williams \& Wilkins; 2013:vol 3, chap 27.

21. Shunmugam M, Shah AN, Hysi PG, Williamson TH. The pattern and distribution of retinal breaks in eyes with rhegmatogenous retinal detachment. Am J Ophthalmol 2014;157:221-226. 
22. Schepens CL, Okamura ID, Brockhurst RJ. The scleral buckling procedures. Surgical techniques and management. AMA Arch Ophthalmol 1957;58(6):797-811.

23. Custodis E. Treatment of retinal detachment by circumscribed diathermal coagulation and by scleral depression in the area of tear caused by imbedding of a plastic implant. Klin Monbl Augenheilkd Augenarztl Fortbild 1956;129(4):476-495.

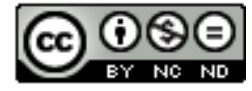

This work licensed under Creative Commons Attribution 